\title{
PILOTS PERFORMANCE AND FLIGHT SAFETY: FLIGHT PHYSIOLOGY IN \\ UNPRESSURIZED AIRCRAFT CABINS
}

Luís Patrão ${ }^{1}$

LaC - Clinical Skills Lab, University of Beira Interior, Covilhã, Portugal

Sara Zorro ${ }^{2}$

LAETA-UBI/AeroG, Aerospace Sciences Department, University of Beira Interior, Portugal

André Marques ${ }^{3}$

LAETA-UBI/AeroG, Aerospace Sciences Department, University of Beira Interior, Portugal

Ana Coelho ${ }^{4}$

LAETA-UBI/AeroG, Aerospace Sciences Department, University of Beira Interior, Portugal

Jorge Silva ${ }^{5}$

LAETA-UBI/AeroG, Aerospace Sciences Department, University of Beira Interior, Portugal

\begin{abstract}
Light aviation pilots are exposed to many different environmental situations due to the unpressurised and unacclimatised aircraft cabins. Literature review suggests that a significant number of incidents and fatalities occurring within this type of aviation are related to human factor. This could be a worrying situation because of various psychophysiological reactions shown by different pilots under the same flight conditions. This study analyses the influence of the flight environmental conditions and the pilot's psychophysiological parameters when performing tasks, and different flight situations, taking some of their everyday habits into consideration. A portable, ergonomic monitoring system was built for the purpose. This system records cerebral oximetry and atmospheric pressure in order to correlate the influence of altitude with the pilot's physiological response in different stages of the flight. It was observed that physiological reactions such as hypoxia and stress, combined with the environmental conditions, can influence the pilot's cognitive response.
\end{abstract}

Keywords: light aviation, psychophysiological parameters, flight conditions, monitoring system, cerebral oximetry, stress.

${ }^{1}$ Luís Patrão is a PhD Student in the field of Aerospace Medicine and a Resident in Internal Medicine. Other appointments include Invited Assistant and Executive Coordinator of the Clinical Skills Lab at FCSUBI. Researcher in Aerospace Medicine, Medical Education, Internal Medicine and Simulation applied to Health Care. Email address: luispatrao@fcsaude.ubi.pt

${ }^{2}$ Sara Zorro is a Medical Student at University of Beira Interior and a PhD Student in Transportation Systems (IST, Lisbon). She holds an MSc in Aeronautical Engineering (UBI, Covilhã) and is a Researcher in Aerospace Physiology and Flight Safety at LAETA/UBI-AeroG. Email address: saramzorro@gmail.com (Corresponding Author)

3 André Marques is an Aeronautical Engineer at the Aeronautics and Space Division at Edisoft S.A. He holds an MSc in Aeronautical Engineering (UBI, Covilhã). He currently is a Researcher at LAETA/UBI-AeroG. Email address: andremarques02@gmail.com

${ }^{4}$ Ana Coelho is an MSc Student in Aeronautical Engineering at University of Beira Interior (UBI, Covilhã). Several of her works have been presented and published in International Scientific Meetings. Email address: catarinacoelho26@gmail.com

${ }^{5}$ Jorge Silva is an Assistant Professor in the Department of Aerospace Sciences of the University of Beira Interior (Portugal). He holds a PhD in Transportation (IST, Lisbon). He is a Member of the American Institute of Aeronautics and Astronautics (AIAA). Email address: jmiguel@ubi.pt 


\section{INTRODUCTION}

Gliding and ultralight aviation have been growing in popularity in Portugal in the past few years, and with it comes the responsibility to make these activities even safer for both those in the air and those on the ground. At the same time, it has been found that accidents and incidents with no apparent mechanical cause have increased. Moreover, after returning from their flights some pilots reported having noticed in themselves, while at the controls, symptoms as euphoria, decreased reaction time, and inability to perform simple tasks (Rocha, 2011). These symptoms imply a variation in the psychophysiological response compatible with the phenomenon of hypoxia which, in terms of flight safety, could represent a worrying situation.

The Flight Physiology concept is taken very seriously in commercial and military aviation, but the competent authorities in general aviation have neglected its applicability to pilots who fly in unpressurised and unacclimatised aircraft cabins, specifically pilots of gliders, ultralights and light aircrafts. This is an even more serious problem since general sport aviation is today a booming business throughout the world, and the regulatory frameworks of different countries have failed to keep up with this growth and are lagging behind in terms of current reality and needs.

The International Civil Aviation Organization (ICAO) and the European Aviation Safety Agency (EASA) do not require any type of ground training in flight physiology. However, Title 14 of the US Code of Federal Regulations (e-CFR), Part 61.31, states, for pilots, flight instructors and ground instructors, "Additional training required for operating pressurized aircraft capable of operating at high altitudes", with certain exceptions (USA Government, 2013). None of the current international regulations require altitude chamber training (ACT).

As a consequence of the Helios Airways Boeing 737-31S accident, at Grammatiko in 2005, the investigation report recommended to EASA and to the Joint Aviation Authorities (JAA) that practical hypoxia training should be required as a mandatory part of flight crew and cabin crew training (Air Accident Investigation \& Aviation Safety Board, 2006). The main constraint of high altitude is that although the percentage of oxygen remains constant up to the stratosphere, with increasing altitude the atmospheric pressure and the partial pressure of oxygen in ambient air and alveolar air fall because gas exchange is reduced, which leads to hypoxia.

The appearance and intensity of the symptoms of hypoxia depend on factors like the speed of ascent, the absolute flight altitude, the duration of exposure to low atmospheric pressure 
and the temperature, along with individual characteristics such as disease, everyday habits, fitness, acclimatisation and stress. Symptoms such as fatigue, drowsiness, dizziness, headache, and euphoria can occur too, since exposure to this phenomenon leads to vision and hearing becoming impaired, reasoning becoming faulty, and the possibility of memory loss and slow and uncoordinated reactions (Alves et al., 2008; Thomas and Douglas, 2002).

Fatigue is a very common symptom that is frequently associated with pilot error, since it can seriously influence the susceptibility to hypoxia and the ability to make effective decisions. Factors like stress and prolonged performance of cognitive work result in mental fatigue (U.S Department of Transportation, 2009).

Time of Useful Consciousness (TUC) is defined as the time elapsing between the loss of supplemental oxygen and the failure of performance. TUC is a parameter that can be determined experimentally in a hypobaric chamber (low pressure simulation), through psychomotor tests, and with "physical activity, even moderate, the TUC reduces up to 50\%" (Alves et al., 2008:252). TUC decreases as altitude increases and, depending on the activity of the individual at the time of oxygen failure, their physical condition, their daily habits and other parameters, the window of opportunity, i.e., TUC, can vary between individuals. Smoking is one factor that dramatically reduces tolerance to lack of oxygen; it can lower an individual's capacity at about 3,000 to 6,000 feet. The TUC for an average smoker at 15,000 feet would be between 10 to 20 minutes, while for a non-smoker it would be about 30 minutes or more (Yoneda and Watanabe, 1997). In situations of rapid depressurisation, TUC is reduced by half (Wolff, 2006).

The human body has different physiological reactions to different environmental scenarios. When flying in an unpressurised aircraft the changes in the cabin environment can be significant, and so the acquisition of physiological parameters is very important.

\section{EXPERIMENTAL WORK}

\subsection{Monitoring System}

This work follows a previous study (Rocha, 2011) where a monitoring system for brain oximetry was tested on ultralight pilots under real flight conditions. In this research, a flight data recorder was assembled along with the cerebral oximeter to record the atmospheric pressure inside the aircraft cabin. Both items of equipment were synchronised to the same time scale to allow the physiological and flight data to be compared. 
The experimental tests were performed by three male individuals with different characteristics (Table 1), where the individual 1 was an inexperienced pilot, with a few hours of real flight and no hypobaric chamber training. Individual 2 was a much older pilot, with many flying hours as an instructor and pilot, and considerable hypobaric chamber training. Individual 3 was a young pilot but with many flight hours and only one hypobaric chamber training session.

Table 1: Characteristics of the Tested Individuals.

\begin{tabular}{cccccc}
\hline Individual & Gender & Age & Physical Exercise & Smoker & $\begin{array}{c}\text { rSO2 (\%) } \\
\text { (mean value at rest) }\end{array}$ \\
\hline 1 & Male & 25 & Rare & No & 78 \\
2 & Male & 60 & Assiduous & No & 62 \\
3 & Male & 25 & Rare & No & 77 \\
\hline
\end{tabular}

In all the figures that follow, only one lobe was monitored with cerebral oximetry since the values for each lobe were approximately the same.

\subsection{Hypobaric Chamber Tests}

Two different hypobaric chamber tests were performed and both took place in the Centro de Medicina Aeronáutica of the Portuguese Air Force, at the Lumiar military base, in Lisbon, Portugal (Table 2).

Table 2: Characteristics of the Hypobaric Chamber Tests

\begin{tabular}{cccc}
\hline Tests & Participating Individuals & Maximum Altitude (feet) & Duration (minutes) \\
\hline 1 & 1 and 2 & $9,577.9$ & 12 \\
2 & 3 & $8,460.8$ & 7 \\
\hline
\end{tabular}

The cerebral oximetry and pressure values were measured throughout the simulation. In Figure 1 it can be seen that at the beginning of the first test, the cerebral regional oxygen saturation ( $\mathrm{rSO} 2$ ) value was $77.5 \%$ for individual 1 and $62.5 \%$ for individual 2, which was the maximum absolute value recorded over the entire test. From that moment, the rSO2 mean value decreased almost continuously for Individual 1 until around 00:07:52 (hours:minutes:seconds), when it reached the absolute minimum of $71 \%$. That was approximately two minutes before the point when the maximum altitude was reached, about $9,577.9 \mathrm{ft}$. For Individual 1, the rSO2 mean value for the entire flight was $76.2 \%$, with a standard deviation of $1.96 \%$. It can also be seen that the rSO2 value for Individual 2 remains practically the same for the entire test, with an absolute minimum value of $59 \%$ by 
the time the maximum altitude was reached, and with a mean value of $61.4 \%$ and a standard deviation of $1.33 \%$.

Figure 1: rSO2 and Altitude Variation During the First Hypobaric Chamber Test

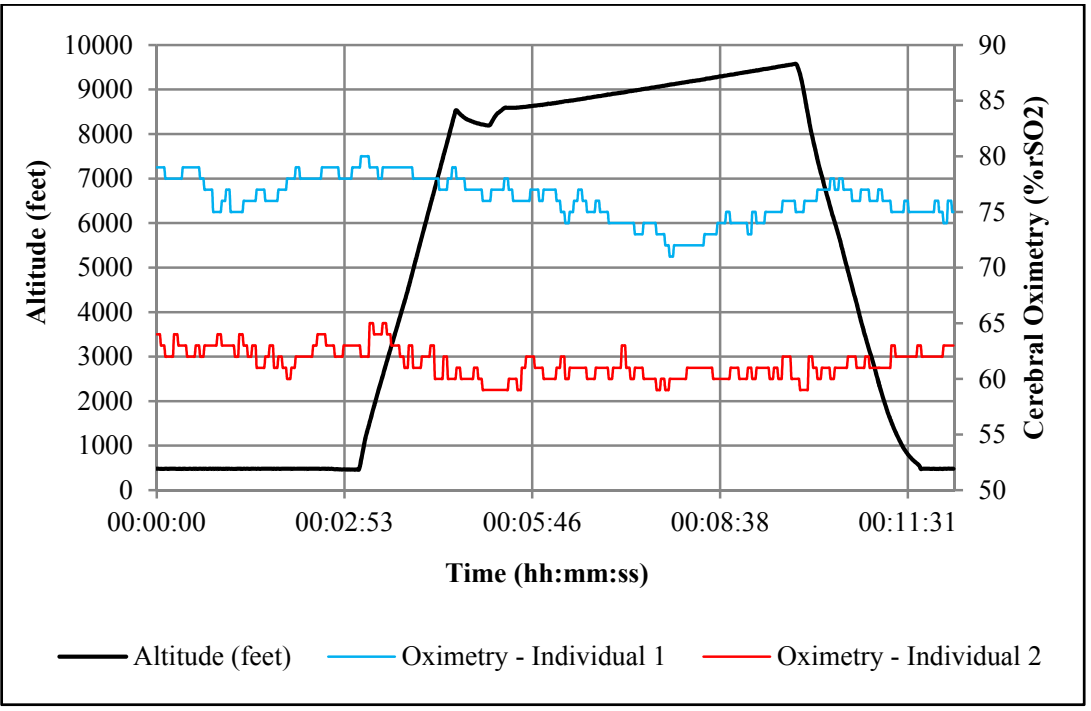

Figure 2: rSO2 and Altitude Variation During the Second Hypobaric Chamber Test

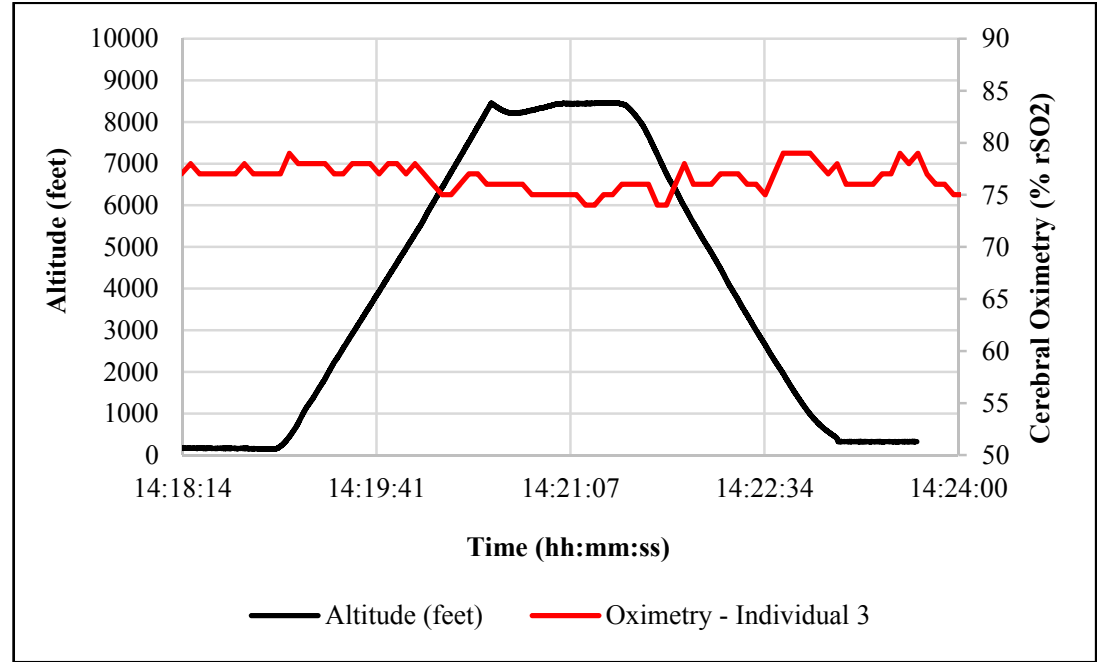

Figure 2 shows that at the beginning of the second test, the rSO2 mean value for individual 3 was $76.2 \%$. From that moment, the rSO2 mean value decreased slightly until around $14: 21: 19$ (hours:minutes:seconds), when it reached the absolute minimum of $74 \%$. That is approximately the point when the maximum altitude was reached, about 8,460.8 $\mathrm{ft}$. The rSO2 mean value of the flight was $75.9 \%$, with a standard deviation of $1.9 \%$.

\subsection{Real Flight Tests}

Five real flight tests were carried out (Table 3). The three flights performed by Individual 2 took place at Tires airfield, in Cascais, Portugal, while the other two took place at Viseu airfield, also in Portugal. 
Table 3: Characteristics of the Flights

\begin{tabular}{|c|c|c|c|c|}
\hline $\begin{array}{l}\text { Real Flight } \\
\text { Tests }\end{array}$ & Individual & $\begin{array}{c}\text { Maximum Altitude } \\
\text { (feet) }\end{array}$ & $\begin{array}{c}\text { Duration } \\
\text { (hh:mm:ss) }\end{array}$ & Observations \\
\hline 1 & 2 & 2,677 & $02: 25: 44$ & $\begin{array}{c}\text { Calm Wind; Smooth } \\
\text { Flight }\end{array}$ \\
\hline 2 & 2 & 3,313 & $00: 54: 32$ & $\begin{array}{l}\text { Strong Wind; } \\
\text { Turbulent Flight. }\end{array}$ \\
\hline 3 & 2 & 6,433 & $02: 56: 04$ & $\begin{array}{l}\text { Calm Wind; } \\
\text { Smooth Flight. }\end{array}$ \\
\hline 4 & 1 & 8,394 & $00: 51: 32$ & $\begin{array}{c}\text { Calm Wind; } \\
\text { Flight with some } \\
\text { intense manoeuvres. }\end{array}$ \\
\hline 5 & 3 & 8,478 & 01:05:26 & $\begin{array}{l}\text { Calm Wind; } \\
\text { Smooth Flight. }\end{array}$ \\
\hline
\end{tabular}

Figure 3 shows that at the beginning of the first test (1), the rSO2 mean value was $63.5 \%$, and after the first ascent, at 11:19:04, it reached the $67 \%$, which corresponded to the maximum absolute value recorded over the entire test. From that moment, the rSO2 mean value was approximately the same throughout the test, with a mean value of $63.3 \%$ and a standard deviation of $1.33 \%$.

Figure 3: Altitude and rSO2 Variation During the Real Rlight, Test 1

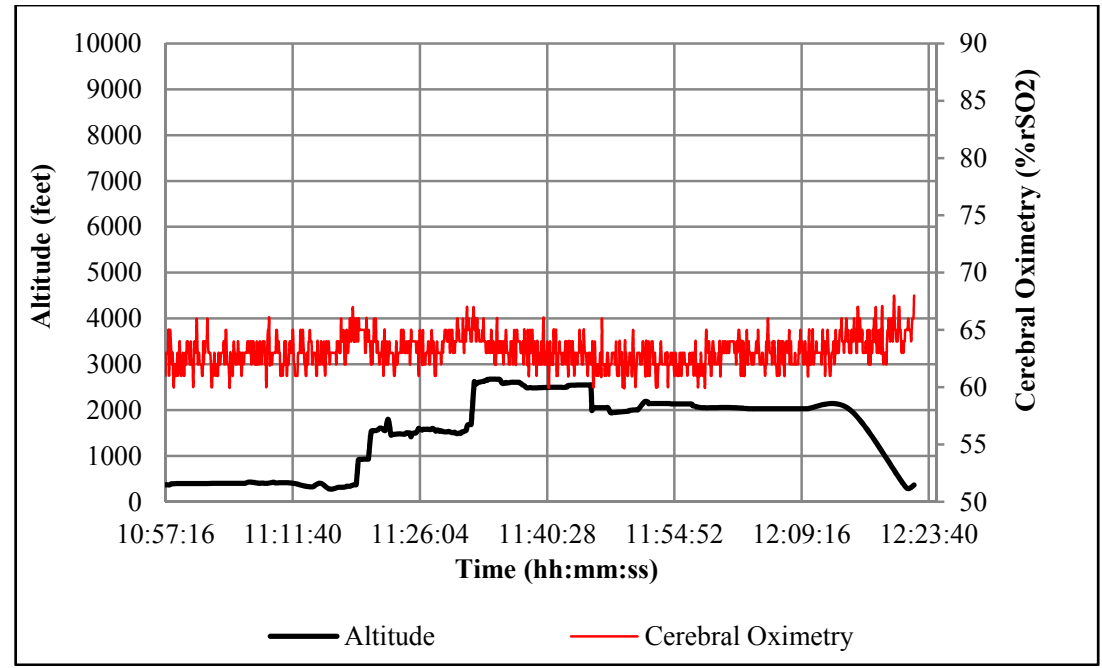

In Figure 4 it can be seen that at the beginning of the second real flight test the rSO2 mean value was 64.5\%; after the first climb (14:50:24), at 1,030 ft, the rSO2 reached a relative maximum value of $69 \%$, and by the end of the second climb (15:09:13), at 3,256 ft, it reached its maximum absolute value recorded throughout the test, $70 \%$. Apart from the moments specified above, the rSO2 mean value was practically the same throughout the test, with a mean value of $64.5 \%$ and a standard deviation of $1.66 \%$. 
Figure 4: Altitude and rSO2 Variation During the Real Flight, Test 2

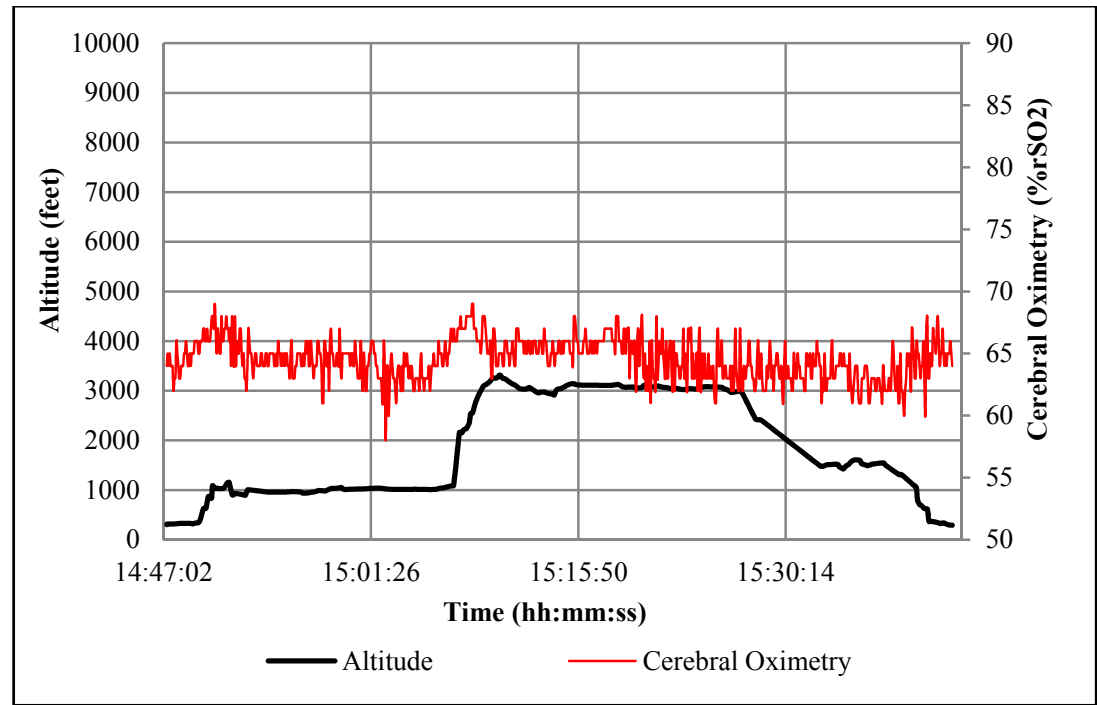

Figure 5 shows that at the beginning of the third real flight test the rSO2 mean value was $62 \%$; at the moment before the first descent $(15: 52: 25)$, at 6,264 feet, it reached a minimum value of $56 \%$, and then started to increase until the end of the first descent (16:36:21), at 633 feet. The oscillation of the rSO2 values then becomes higher and by the start of the second descent (17:21:29), at 6,270 feet, it starts increasing until the end of the flight. The rSO2 mean value during the flight was $61.8 \%$, with a standard deviation of $2.7 \%$.

\section{Figure 5: Altitude and rSO2 Variation during the Real Flight, Test 3}

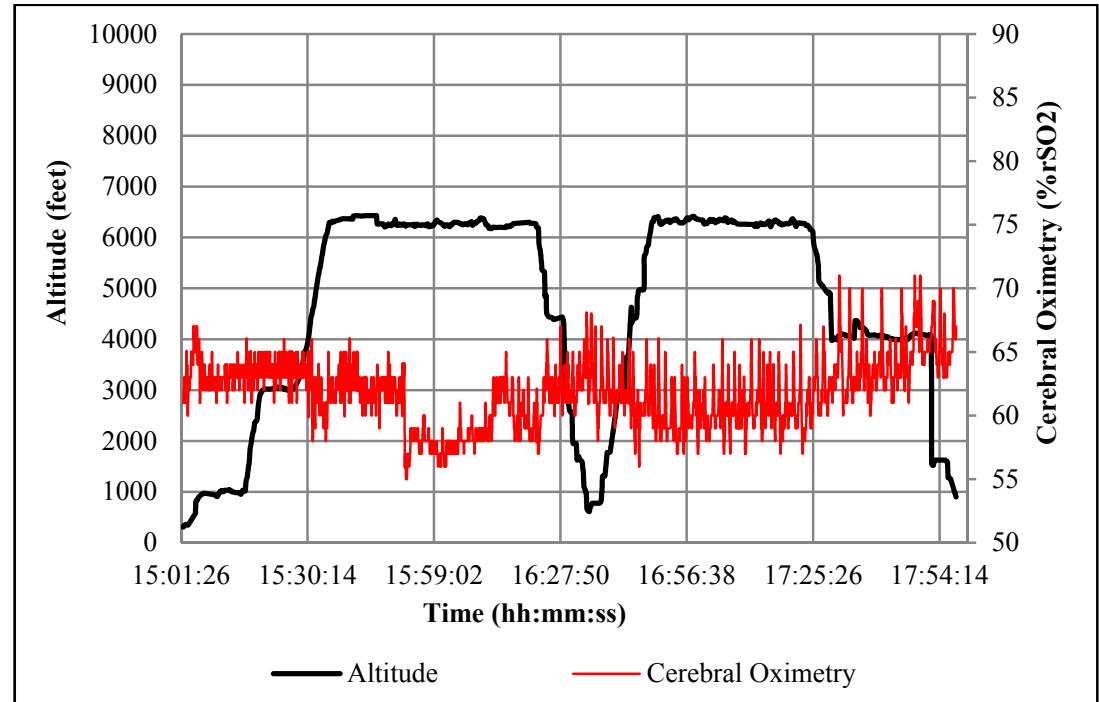

In Figure 6 it can be seen that at the beginning of the fourth real flight test, the rSO2 mean value was $81 \%$, which corresponded to the maximum absolute value recorded throughout the test. The minimum rSO2 absolute value of $74 \%$ was recorded when the maximum altitude was reached (15:15:57). Apart from those moments, the rSO2 mean value was 
practically the same throughout the test, with a mean value of $78.8 \%$ and a standard deviation of $1.76 \%$.

Figure 6: Altitude and rSO2 Variation During the Real Flight, Test 4

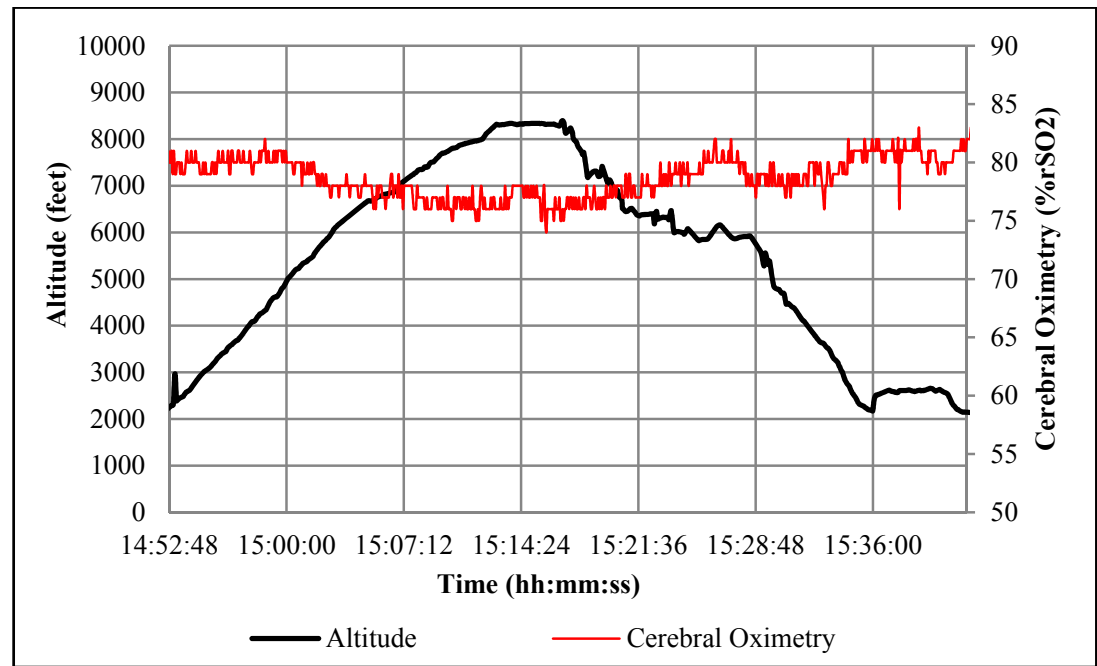

Figure 7: Altitude and rSO2 Variation During the Real Flight, Test 5

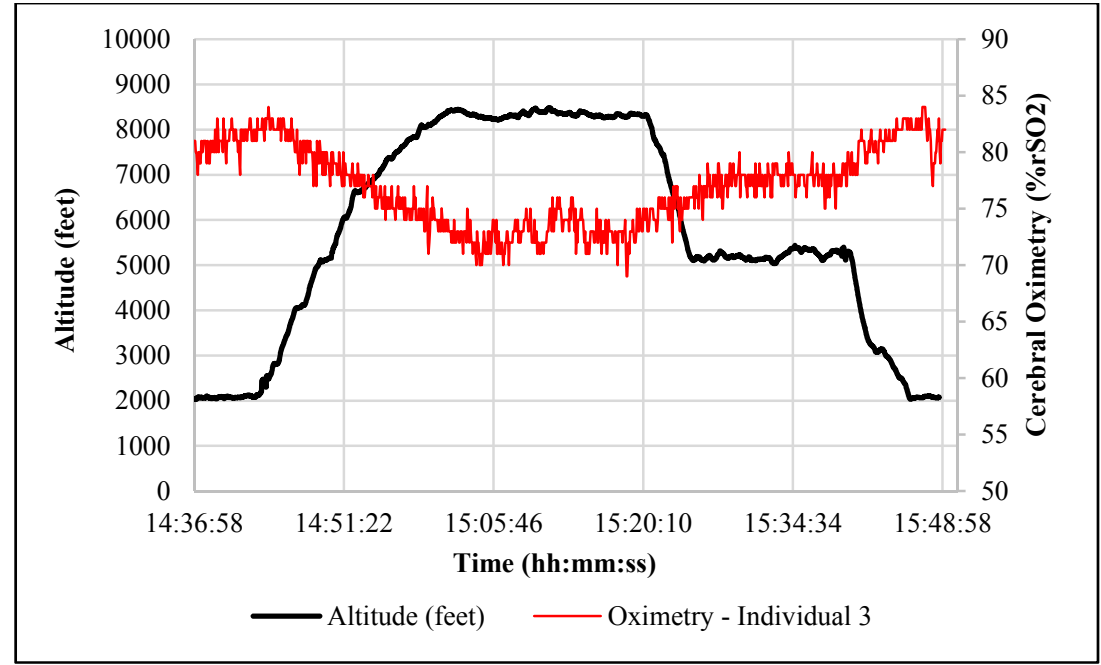

In Figure 7 can be seen that at the beginning of the fifth real flight test, the rSO2 mean value was $82 \%$, which corresponded to the maximum absolute value recorded throughout the test. The minimum rSO2 absolute value of $69 \%$ was recorded when the maximum altitude was reached $(15: 18: 34)$. The rSO2 mean value during the flight was $77.5 \%$, with a standard deviation of $3.4 \%$.

\section{DISCUSSION - EXPERIMENTAL WORK}

The comparison of cerebral oximetry with the altitude variation in the hypobaric chamber tests showed that, in the both tests, where the maximum altitude reached was 9,577.9 feet and $8,460.8$ feet, respectively, the rSO2 variation between the minimum and maximum altitude was $1.5 \%$ for Individual $1,3.5 \%$ for Individual 2 and $2.2 \%$ for Individual 3 (Table 
4). Interestingly, it was Individual 2, who was a flight instructor with many hours of experience and many hypoxia training sessions in a hypobaric chamber who showed a greater variation of rSO2 than the two much younger individuals. For individuals 1 and 3, these were their first and the second experiences in the hypobaric chamber, respectively. As such, differences in age, physical characteristics and life habits could be very relevant factors for the disparity of values.

\section{Table 4: Results of the Hypobaric Chamber Tests, Altitude VS rSO2, for Each Individual}

\begin{tabular}{|c|c|c|c|c|c|}
\hline \multicolumn{2}{|c|}{ Individual 1} & \multicolumn{2}{|c|}{ Individual 2} & \multicolumn{2}{|c|}{ Individual 3} \\
\hline $\begin{array}{l}\text { Minimum } \\
\text { Altitude } \\
(0 \mathrm{ft})\end{array}$ & $77.5 \%(\mathrm{rSO})$ & $\begin{array}{l}\text { Minimum Altitude } \\
\qquad(0 \mathrm{ft})\end{array}$ & $62.5 \%(\mathrm{rSO})$ & $\begin{array}{c}\text { Minimum } \\
\text { Altitude } \\
(0 \mathrm{ft})\end{array}$ & $76.2 \%(\mathrm{rSO} 2)$ \\
\hline $\begin{array}{l}\text { Maximum } \\
\text { Altitude } \\
(9,577.9 \mathrm{ft})\end{array}$ & 76\% (rSO2) & $\begin{array}{c}\text { Maximum Altitude } \\
(9,577.9 \mathrm{ft})\end{array}$ & $\mathbf{5 9 \%}(\mathrm{rSO} 2)$ & $\begin{array}{l}\text { Maximum } \\
\text { Altitude } \\
(8,460.8 \mathrm{ft})\end{array}$ & $74 \%(\mathrm{rSO})$ \\
\hline $\begin{array}{c}\text { Altitude for } \\
\text { minimum rSO2 } \\
\text { value } \\
(9,200 \mathrm{ft})\end{array}$ & $\underline{\mathbf{7 1} \%}$ (rSO2) & $\begin{array}{l}\text { Altitude for minimum } \\
\text { rSO2 value } \\
(9,577.9 \mathrm{ft})\end{array}$ & $\underline{\mathbf{5 9} \%}(\mathrm{rSO})$ & $\begin{array}{l}\text { Altitude for } \\
\text { minimum } \\
\text { rSO2 value } \\
(8,460.8 \mathrm{ft})\end{array}$ & $\underline{74 \%}$ (rSO2) \\
\hline
\end{tabular}

Table 5: Results of the Hypobaric Chamber Tests, Altitude VS rSO2, for Individual 2

\begin{tabular}{|c|c|c|c|c|c|}
\hline \multicolumn{2}{|c|}{ Real Flight 1} & \multicolumn{2}{|c|}{ Real Flight 2} & \multicolumn{2}{|c|}{ Real Flight 3} \\
\hline $\begin{array}{c}\text { Minimum } \\
\text { Altitude } \\
(0 \mathrm{ft})\end{array}$ & $\begin{array}{l}63.5 \% \\
(\mathrm{rSO} 2)\end{array}$ & $\begin{array}{l}\text { Minimum Altitude } \\
\qquad(0 \mathrm{ft})\end{array}$ & $64.5 \%(\mathrm{rSO})$ & $\begin{array}{l}\text { Minimum } \\
\text { Altitude } \\
(0 \mathrm{ft})\end{array}$ & $62 \%(\mathrm{rSO})$ \\
\hline $\begin{array}{l}\text { Maximum } \\
\text { Altitude } \\
(2,677 \mathrm{ft})\end{array}$ & $67 \%(\mathrm{rSO})$ & $\begin{array}{l}\text { Maximum Altitude } \\
\qquad(3,313 \mathrm{ft})\end{array}$ & 69\% (rSO2) & $\begin{array}{l}\text { Maximum } \\
\text { Altitude } \\
(6,433 \mathrm{ft})\end{array}$ & $66 \%(\mathrm{rSO})$ \\
\hline $\begin{array}{c}\text { Altitude for } \\
\text { minimum rSO2 } \\
\text { value } \\
(2,500 \mathrm{ft})\end{array}$ & $\underline{60 \%}(\mathrm{rSO})$ & $\begin{array}{c}\text { Altitude for } \\
\text { minimum rSO2 } \\
\text { value } \\
(1,000 \mathrm{ft})\end{array}$ & $\underline{58 \%}(\mathrm{rSO} 2)$ & $\begin{array}{l}\text { Altitude for } \\
\text { minimum } \\
\text { rSO2 value } \\
(6,264 \mathrm{ft})\end{array}$ & $\underline{56 \%}(\mathrm{rSO})$ \\
\hline
\end{tabular}

In the real flight tests, the rSO2 variation between the minimum and maximum altitude, was $3.5 \%$ for test $1,4.5 \%$ for test $2,4 \%$ for test $3,7 \%$ for test 4 , and $13 \%$ for test 5 (Table 5 
and Table 6). However, it was found that in all the three real flights the minimum value of rSO2 for Individual 2 did not occur as expected, when the maximum altitude was reached. Such inconsistency does not have an obvious justification because there is too little information available for this type of study, so we can speculate that it might be due to psychophysiological characteristics, such as age, stress or even the reaction time that the human body takes to respond to the external environment.

Table 6: Results of the Real Flight Tests, Altitude VS rSO2, for Individuals 1 and 3

\begin{tabular}{|c|c|c|c|}
\hline $\begin{array}{l}\text { Individual } 1 \\
\text { Real Flight } 4\end{array}$ & & \multicolumn{2}{|c|}{$\begin{array}{l}\text { Individual } 3 \\
\text { Real Flight } 5\end{array}$} \\
\hline $\begin{array}{l}\text { Minimum Altitude } \\
\qquad(0 \mathrm{ft})\end{array}$ & $81 \%(\mathrm{rSO} 2)$ & $\begin{array}{l}\text { Minimum Altitude } \\
\qquad(0 \mathrm{ft})\end{array}$ & $82 \%(\mathrm{rSO} 2)$ \\
\hline $\begin{array}{l}\text { Maximum Altitude } \\
\qquad(8,394 \mathrm{ft})\end{array}$ & $74 \%(\mathrm{rSO})$ & $\begin{array}{l}\text { Maximum Altitude } \\
\qquad(8,478 \mathrm{ft})\end{array}$ & $69 \%(\mathrm{rSO} 2)$ \\
\hline $\begin{array}{c}\text { Altitude for minimum rSO2 } \\
\text { value } \\
(8,394 \mathrm{ft})\end{array}$ & $\underline{74 \%}$ (rSO2) & $\begin{array}{l}\text { Altitude for minimum } \\
\text { rSO2 value } \\
(8,478 \mathrm{ft})\end{array}$ & $\underline{69 \%}(\mathrm{rSO} 2)$ \\
\hline
\end{tabular}

Also, from the cerebral oximetry analysis of the three individuals for both types of test, it can be seen that they have different basal values of $\mathrm{rSO}$, which may be due to having different daily habits and physical characteristics, and that sporadic peak values occur because none of the individuals were completely immobile and therefore there was the risk of poor contact with the cerebral oximetry sensors. However, these data have yet to be carefully analysed by clinicians with expertise in determining if significant changes have occurred that could constrain psychophysiological capacity and, consequently, compromise flight safety.

The results do nonetheless suggest that the human body can be trained to adapt to different situations and that, when in an unknown environment, the arousal and the stress levels can compromise the rSO2 values and the normal response to an external stimulus, by physiologically increasing its intensity, i.e. increasing the state of hypoxia.

\section{FINAL REMARKS}

This study involved several experimental flights, where it was only possible to extract the full data from those discussed in this paper. This factor is the main reason for the small number 
of experimental tests. However, despite its limitations this study provides interesting and useful information that can make a positive contribution to flight safety.

Another intrinsic part of this research is flight simulator tests (in progress), the purpose of which is to study a pilot's psychophysiological behaviour in situations of great responsibility where attention and concentration are vital.

\section{ACKNOWLEDGEMENTS}

Thanks are due to: FCT (Foundation for Science and Technology) for the MSc grant awarded to Sara Zorro and André Marques under the AIRDEV (Business Models for Airport Development and Management) Project in partnership with MIT-Portugal Program (Reference: MIT-Pt-TSAAs/0046/2008); to Nonin Medical Inc.; to Centro de Medicina Aeronáutica of the Portuguese Air Force; to OMNI Aviation Training Center; to the Faculty of Health Sciences, the Department of Sport Sciences and the Department of Informatics of University of Beira Interior; and to pilots David Marques and Bernardo Pereira, for their interest in and support of this project.

\section{REFERENCES}

- Air Accident Investigation \& Aviation Safety Board (AAIASB) (2006), Helios Airways Flight HCY522 Boeing 737-31S at Grammatiko, Hellas on 14 August 2005, Hellenic Republic Ministry of Transport \& Communications. Available from: www.moi.gov.cy/moi/pio/pio.nsf/all/F15FBD7320037284C2257204002B6243/\$file/FINAL \%20REPORT\%205B-DBY.pdf (accessed on 10/01/2013).

- Alves, L., Ribeiro, A., Brandão, L., Teixeira, R. and Bisol, T. (2008), 'Avaliação dos efeitos da altitude sobre a visão', Rev. Bras. Oftalmologia, vol. 67, no. 5, pp. 250-254.

- Code of Federal Regulations, 14 CFR, Chapter I, Part 61, Certification: pilots, flight instructors, and ground instructors. Subpart - $A$ 61.31. Available from: http://ecfr.gpoaccess.gov/cgi/t/text/textidx?c=ecfr\&rgn=div5\&view=text\&node=14:2.0.1 1.2\&idno=14\#14:2.0.1.1.2.1.1.21 (accessed on 28/01/2013).

- Rocha, L. (2011), 'Desempenho de Pilotos e Segurança de Voo: O Caso da Hipoxia em Aviação Desportiva', Master Thesis in Aeronautical Engineering, University of Beira Interior, Covilhã.

- Thomas, J. and Douglas, J. (2002), 'Ophthalmology in aerospace medicine'. In: DeHart, R. and Davis, J. (ed.), Fundamentals of Aerospace Medicine, Philadelphia: Lippincott Williams \& Wilkins, $3^{\text {rd }}$ edition, pp. 362-450.

- U.S Department of Transportation (2009), Pilot's Handbook of Aeronautical Knowledge, Federal Aviation Administration, FAA-H-8083-25A, pp. 16-12. 
- Wolff, M. (2006), 'Cabin Decompression and Hypoxia', PIA Air Safety Publication. Available from: www.TheAirlinePilots.com (accessed on 18/05/2013).

- Yoneda, I. and Watanabe, Y. (1997), 'Comparisons of altitude tolerance and hypoxia symptoms between non-smokers and habitual smokers', Aviation, Space, Environment and Medicine, vol. 68, no. 9, pp. 807-811. 